\title{
Implications of considering metal bioavailability in estimates of freshwater ecotoxicity: examination of two case studies
}

\author{
Nilima Gandhi • Miriam L. Diamond • \\ Mark A. J. Huijbregts • Jeroen B. Guinée • \\ Willie J. G. M. Peijnenburg • Dik van de Meent
}

Received: 13 April 2011 / Accepted: 20 June 2011 /Published online: 13 July 2011

(C) The Author(s) 2011. This article is published with open access at Springerlink.com

\begin{abstract}
Purpose Previous methods of estimating characterization factors (CFs) of metals in life cycle impact assessment (LCIA) models were based on multimedia fate, exposure, and effect models originally developed to address the potential impacts of organic chemicals. When applied to metals, the models neglect the influence of ambient chemistry on metal speciation, bioavailability and toxicity. Gandhi et al. (2010) presented a new method of calculating
\end{abstract}

Responsible editor: Andreas Jørgensen

Electronic supplementary material The online version of this article (doi:10.1007/s11367-011-0317-3) contains supplementary material, which is available to authorized users.

\section{N. Gandhi}

Department of Chemical Engineering and Applied Chemistry,

University of Toronto,

45 St. George Street,

Toronto, ON M5S 2E5, Canada

M. L. Diamond $(\bowtie)$

Department of Geography, University of Toronto,

100 St. George Street,

Toronto, ON M5S 3G3, Canada

e-mail: miriam.diamond@utoronto.ca

M. A. J. Huijbregts · D. van de Meent

Department of Environmental Science, Faculty of Science,

Radboud University,

Toernooiveld 1,

6500 GL, Nijmegen, The Netherlands

J. B. Guinée · W. J. G. M. Peijnenburg Institute of Environmental Sciences, Leiden University, P.O. Box 9518, 2300 RA, Leiden, The Netherlands

W. J. G. M. Peijnenburg • D. van de Meent Laboratory of Environmental Risk Assessment, National Institute of Public Health and the Environment (RIVM), Bilthoven, The Netherlands
CFs for freshwater ecotoxicity that addresses these metalspecific issues. In this paper, we compared and assessed the consequences of using the new method versus currently available LCIA models for calculating freshwater ecotoxicity, as applied to two case studies previously examined by Gloria et al. (2006): (1) the production of copper $(\mathrm{Cu})$ pipe and (2) a zinc (Zn) gutter system.

Methods Using the same inventory data as presented by Gloria et al. (2006), we calculated and compared the LCIA outcomes for freshwater ecotoxicity of each case study using four models: USES-LCA 1.0, USES-LCA 2.0, USEtox $^{\mathrm{TM}}$ using the previous approach, and USEtox ${ }^{\mathrm{TM}}$ using the new method. Since the new method requires specification of water chemistry for the freshwater compartment, we explored the effect of using seven freshwater archetypes. We analyzed the freshwater ecotoxicity outcomes of the two case studies with respect to the different models, infinite versus 100 years time scales for calculating impacts after metal emissions, and water chemistries representing environmental variability.

Results and discussion Significant differences in CFs, overall freshwater ecotoxicity score $(\Sigma \mathrm{CF} \times$ emissions) and the contributions of individual metals to the overall score were traced back to differences in modeling methods (e.g., variations in compartments included in the fate model), the choice of metal partition coefficients versus those explicitly calculated based on water chemistry (USEtox $^{\mathrm{TM}}$ (new)), and the calculation of effect factors. Metal CFs calculated using USES-LCA 1.0 ranked $\mathrm{Co}>\mathrm{Ni}>$ $\mathrm{Cd} \approx \mathrm{Cu}>\mathrm{Zn}>\mathrm{Pb}$, but changed using USEtox ${ }^{\mathrm{TM}}$ (new) to $\mathrm{Cd}>$ $\mathrm{Co}>\mathrm{Ni}>\mathrm{Zn}>\mathrm{Cu}>\mathrm{Pb}$ for the archetype of hard alkaline water and $\mathrm{Cd}>\mathrm{Ni}>\mathrm{Co}>\mathrm{Cu} \approx \mathrm{Zn}>\mathrm{Pb}$ for the archetype of soft, acidic water. For the $\mathrm{Cu}$ pipe, total freshwater ecotoxicity scores for metal emissions into air and water ranged from 0.01 to 0.02 for USES-LCA1.0, $\sim 1$ for USEtox ${ }^{\mathrm{TM}}$ (previous) to 0.0002 
0.01 1, 4-dichlorobenzene (DCB) eq. for USEtox ${ }^{\mathrm{TM}}$ (new) depending on the archetype. Whereas $\mathrm{Cu}$ followed by $\mathrm{Ni}$ emissions contributed most to total freshwater ecotoxicity estimated by USES-LCA1.0, $\mathrm{Cu}, \mathrm{Cd}, \mathrm{Ni}$, and $\mathrm{Zn}$, emissions were all important contributors towards freshwater ecotoxicity with USEtox ${ }^{\mathrm{TM}}$ (new), with differences in contributions dependent on the freshwater archetype. For the $\mathrm{Zn}$ gutter case study, the total scores varied from 10 for USEtox ${ }^{\mathrm{TM}}$ (previous) to 0.008 for USES-LCA 2.0 and $0.02-0.11$ equal to $1,4-\mathrm{DCB}$ for USEtox ${ }^{\mathrm{TM}}$ (new). Zn contributed $\sim 98 \%$ towards the freshwater ecotoxicity scores of metals in all models. For both case studies, differences in ecotoxicity scores were not significant for the infinite vs. 100 years time scale.

Conclusions Accounting for metal bioavailability and speciation by using USEtox ${ }^{\mathrm{TM}}$ (new) when calculating CFs decreased by $1-4$ orders of magnitude the total metal freshwater ecotoxicity scores $(\Sigma \mathrm{CF} \times$ emissions $)$ attributable to metal emissions tallied for $\mathrm{Cu}$ pipe and $\mathrm{Zn}$ gutter system case studies (Gloria et al. 2006). This broad range came from the model used in comparison to USEtox ${ }^{\mathrm{TM}}$ (new) and the choice of freshwater archetype. Additionally, contributions of each metal to the total score of the $\mathrm{Cu}$ pipe case study changed significantly from the use of previous CFs (Huijbregts et al. 2000) versus the revised CFs (Gandhi et al. 2010).

Practical implications Metal CFs calculated using the method proposed by Gandhi et al. (2010) significantly lowers the total freshwater ecotoxicity impact of metal emissions. It is suggested that this lower estimate of potential impact from metal emissions is consistent with our understanding of metal chemistry. The magnitude of the potential freshwater ecotoxicity of metals depends on the chemistry of the modeled freshwater compartment, similarly to the dependence of acidification potential on regionally variant freshwater chemistry.

Keywords Ambient chemistry. Bioavailability. Comparative toxicity potential (CTP) - Life cycle impact assessment (LCIA) · Metals · Speciation-complexation

\section{Introduction}

Nonferrous metals, in their numerous inorganic and organic forms, often rise to the top of toxicity concerns in life cycle assessment (LCA). This is not necessarily because of the inherent hazard of metals, but because the tools used for life cycle impact assessment (LCIA) do not incorporate the complex and seemingly idiosyncratic behavior of metals. A concern that metal hazard has been overestimated using available screening tools was expressed in several fora. The Lausanne review workshop (Jolliet et al. 2006) and the Apeldoorn Declaration (Apeldoorn 2004) expressed the consensus view among multisectoral participants that metal-specific properties, speciation, and bioavailability must be considered in the assessment of chemical hazard of metal emissions. At issue is that the tools used to assign characterization factors $(\mathrm{CFs})$, indicative of the relative ecotoxicological hazard of metals, are based on the behavior of organic compounds. For organic compounds, there is a relatively simple dichotomy between bioavailable and nonbioavailable chemical in an evaluative environment. In contrast, metal bioavailability depends on metalspecific speciation which is sensitive to ambient chemistry. Examples of this dependency are the distribution of cationic metals between dissolved and particle phases as a function of $\mathrm{pH}$ and the very strong affinity of $\mathrm{Cu}$ binding to dissolved organic matter (e.g., Adams and Chapman 2005). These differences between the aqueous chemistry of nonferrous metals and organics result in the inconsistent assessment of the relative hazard of nonferrous metals and organics.

The Clearwater Consensus (Diamond et al. 2010), which again assembled a multisectoral group of experts in metal chemistry and LCA, formulated a series of recommendations aimed at eliminating the inconsistencies between the assessment of nonferrous metals and organics in LCIA, hazard, and risk assessment. A key recommendation was to estimate bioavailability by considering metal-specific speciation.

The recommendations of the Clearwater Consensus were incorporated into a new framework proposed by Gandhi et al. (2010) in which bioavailability is explicitly introduced into calculations of metal impact. The revised method addresses metal-specific issues in three stages by estimating: (1) metal bioavailability factors (BFs) using an equilibrium, geochemical speciation model that also calculates metal adsorption to humic material (e.g., Windermere Humic Adsorption Model-WHAM 6.0; Tipping 1998), (2) fate factors (FFs) in USEtox ${ }^{\mathrm{TM}}$ (Rosenbaum et al. 2008) by using metal $K_{d}$ values calculated separately in the geochemical model, and (3) effect factors (EFs) by applying the biotic ligand model (BLM; Di Toro et al. 2001) to correct for metal bioavailability in toxicity assesments of aquatic organisms (e.g., chronic $\mathrm{EC}_{50}$ ). The expression of this three-stage analysis is a final comparative toxicity potential (CTP) that is a numerical indicator of ecotoxicity. The CF is determined by normalizing the CTP of a substance relative to other chemicals under defined model conditions (Gandhi et al. 2010, 2011).

Gloria et al. (2006) explored the consequences of using metal CFs from different LCIA models that do not explicitly account for metal speciation and bioavailability. They examined two case studies: (1) use of $\mathrm{Cu}$ pipe for supplying domestic water and (2) an average Zn-based gutter system for residential use. Their analysis used life cycle inventory (LCI) data for total emissions of various chemicals as part of the cradle-to-grave analysis of both 
case studies. Gloria et al. reported the outcomes of the ecotoxicity impact category as a result of using five different LCIA models to calculate freshwater ecotoxicity potential of metals: USES-LCA 1.0, Eco-indicator 99 (EI 99), IMPACT 2002, EDIP 97, and CalTOX-ETP.

The goal of this paper was to examine the effect on the outcome of the metal case studies presented by Gloria et al. (2006) of using the new method for estimating freshwater ecotoxicity. We calculated and compared metal CFs and LCIA outcomes for freshwater ecotoxicity of each of the two studies using four models: USES-LCA 1.0 (Huijbregts et al. 2000), USES-LCA 2.0 (van Zelm et al. 2009), USEtox $^{\mathrm{TM}}$ using the interim approach (Rosenbaum et al. 2008), and the new method with the geochemical correction in USEtox ${ }^{\mathrm{TM}}$ (Gandhi et al. 2010). We also examined the implications of the choice of freshwater chemistry in this context.

\section{Methods}

\subsection{Case studies}

We revisited the case studies examined by Gloria et al. (2006), first a Cu-based product of $\mathrm{Cu}$ pipe and second a $\mathrm{Zn}$-based gutter system for an average residential application. For $\mathrm{Cu}$ pipe used in a typical American house over its lifetime, Gloria et al. (2006) relied on the comprehensive inventory compiled by Ecobalance (2000a, b) under commission to the International Copper Association that represented data from 31 sites and accounted for $58 \%$ of the $\mathrm{Cu}$ production by refinery and $74 \%$ by solvent extraction. The inventory covered the stages from mining and milling to pipe manufacturing. The second case study was for zinccopper-titanium alloy gutters which are used in $70 \%$ of the residential market in the Netherlands. The $\mathrm{Zn}$ used is a special high-grade $\mathrm{Zn}$ with a purity of $99.995 \%$. The inventory data gathered under commission by TNO-Environment, Energy and Process Innovation was from three manufacturers representing $90 \%$ of the Dutch market. The case study included the gutter, four end pieces of zinc-copper-titanium alloy, and 16 support brackets made of galvanized steel with a $30 \mu \mathrm{m} \mathrm{Zn}$ layer applied to both sides.

Using the same inventory data (Tables S1-S2, Electronic Supplementary Material) reported by Gloria et al. (2006), we calculated metal impact scores for freshwater ecotoxicity $(\Sigma \mathrm{CF} \times$ emissions) using four models listed above. We used these models because they share a similar structure and fate processes that isolate the comparison of metal CFs and thus LCIA results for freshwater ecotoxicity related to these case studies. We did not make any modifications to the modeling structure, default parameterization of fate and exposure processes, or toxicity endpoints in the models.

\subsection{Model applications}

\subsubsection{USES-LCA 1.0}

For five emission compartments, i.e. air, freshwater, sea water, industrial soil, and agricultural soil, USES-LCA 1.0 (Huijbregts et al. 2000) calculates chemical-specific CFs over an infinite time horizon based on FFs and EFs for each compartment. FFs and EFs express the change in the total dissolved concentration of a chemical in a compartment due to a change in its emission (Table 1). The nested multimedia fate model Simplebox 2.0 (Brandes et al. 1996) was the basis of USES-LCA 1.0. Model compartments are defined on the continental and global scales. For the case studies, we used the default environmental properties of the freshwater compartment at the continental scale (see Table 1). EFs were calculated as the inverse of the predicted no effect concentration (PNEC) of a chemical (Huijbregts et al. 2000). A reference chemical 1,4-dichlorobenzene (DCB) was used to normalize freshwater ecotoxicity of metals using the midpoint calculation method (see Table 1). Huijbregts et al. (2000) list CFs calculated for 19 metals normalized to the $\mathrm{CF}$ of $1,4-\mathrm{DCB}$.

\subsubsection{USES-LCA 2.0}

USES-LCA 1.0 was updated to USES-LCA 2.0 (van Zelm et al. 2009). The latter model considers 10 emission compartments, including urban air, rural air, freshwater, and agricultural soil. USES-LCA 2.0 calculates chemicalspecific CFs using FFs and EFs in multiple compartments to assess ecotoxicological impacts over a default infinite time horizon. Similar to USES-LCA 1.0, FFs and EFs represent the change in total dissolved concentration of a chemical in an environmental compartment due to the change in its emission (see Table 1). The updated model Simplebox 3.0 (Den Hollander et al. 2004) forms the basis of USES-LCA 2.0. For the case studies, the default landscape properties of the freshwater compartment at the continental scale were used to calculate metal CFs. Unlike USES-LCA 1.0, EFs were calculated using a slope factor (typically 0.5 ), and a chemical-specific toxic potency factor that reflects the toxicity of a chemical averaged over multiple species (van de Meent and Huijbregts 2005). This value can be interpreted as the dissolved concentration at which $50 \%$ of the species considered are "protected". Again, 1,4-DCB was used as a reference substance in the midpoint calculations to estimate freshwater ecotoxicity of each metal (see Table 1).

For USES-LCA 1.0 and USES-LCA 2.0 models, we also analyzed the effects of varying time scales to analyze environmental impacts after emissions by comparing results for 100 years versus an infinite time scale. This analysis is important because metals are infinitely persistent in 


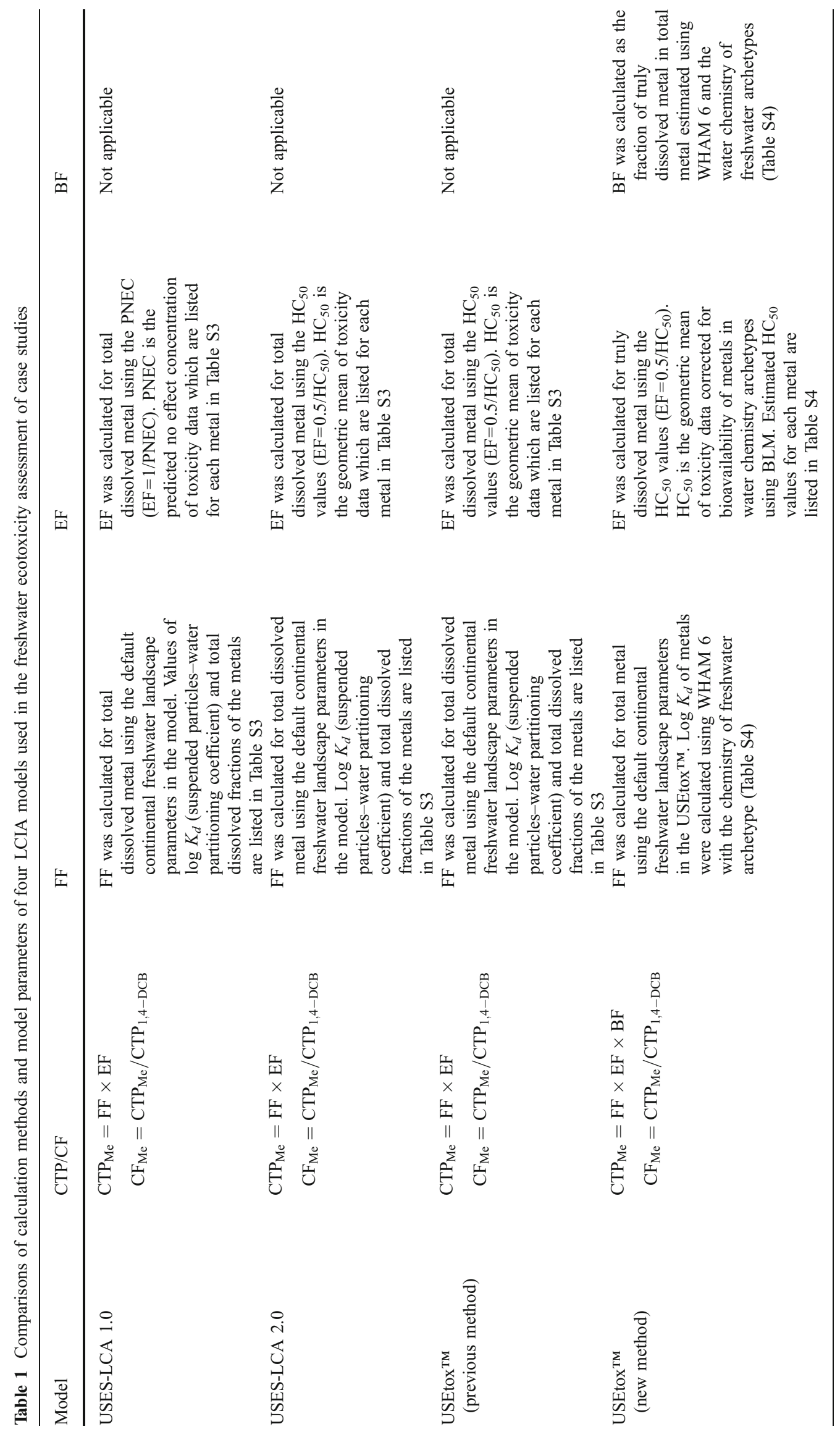


comparison to organic compounds which degrade over time (Pettersen and Hertwich 2008; Huijbregts et al. 2001). One of the approaches proposed in LCA is to separate short- and long-term to infinite time horizons over which environmental impacts are considered after emissions (e.g., Udo de Haes et al. 1999). This distinction of impact period can allow LCA practitioners to use different fate expressions derived from experimental results along with kinetic modeling for estimating mineralization and/or weathering, i.e., the metal release from and incorporation into solid mineral phases over a specified time period. However, in reality, this is rarely or perhaps never has been done because of the paucity of kinetic data and the need to introduce more complexity into the available models. The short-term period is often set at 100 years (e.g., Huijbregts et al. 2000; Finnveden 1999), which is the time span we chose. The default model formulations and parameter values for the 100 years time period were taken from the original USES-LCA 1.0 and USES-LCA 2.0 models (Table S3, Electronic Supplementary Material).

\subsubsection{USEtox $^{\mathrm{TM}}$}

As a result of the life cycle initiative launched by the United Nations Environment Program (UNEP) and the Society for Environmental Toxicology and Chemistry (SETAC) to harmonize several LCIA toxicity characterisation models, the consensus model USEtox ${ }^{\mathrm{TM}}$ has been introduced as a parsimonious and transparent tool to provide CFs for ecotoxicity and human health (Hauschild et al. 2008, Rosenbaum et al. 2008). The model formulation was jointly finalized by the developers of CalTOX, IMPACT 2002, USES-LCA, BETR, EDIP, WATSON, and EcoSense. USEtox ${ }^{\mathrm{TM}}$ assesses toxicological effects of a chemical emitted into a model compartment by considering the three steps of environmental fate, exposure, and effects. A chemical can be emitted into one of the five compartments (e.g., air, freshwater, marine water, and natural and agricultural soil) at both continental and global scales nested in the model structure. Urban air is added as a separate compartment at the continental scale.

The model calculates CTP based on FF and EF (see Table 1). The FF is calculated as the change in total dissolved concentration of a chemical after its emission and represents the compartment-specific residence time in days. The fate calculations differ from the previous models by the inclusion of, for example, intermittent rain and an urban air compartment. The calculation of EF is similar to that in USES-LCA 2.0. A geometric mean of laboratory-derived single species $\mathrm{EC}_{50}$ values (water concentration at which $50 \%$ of a population displays an effect), also known as $\mathrm{HC}_{50}$, is used to represent the concentration-response relationship. Different than USES-LCA 2.0, measured chronic
$\mathrm{EC}_{50}$ values are preferred, however, in case of insufficient chronic data, acute data are used by applying an acute-tochronic extrapolation factor that is set to a default value of 2 (Rosenbaum et al. 2008). For a consistent comparison of model results with those from USES-LCA 1.0 and USESLCA 2.0, we used 1,4-DCB as a reference chemical to normalize metal CFs (see Table 1). Model parameter values used in the calculation of metal CFs are summarized in Table S3, Electronic Supplementary Material.

\subsubsection{USEtox new method}

As mentioned above, Gandhi et al. (2010, 2011) incorporated the recommendations of the Clearwater Consensus to develop a modeling method for metals that accounts for the effect of geochemical speciation on freshwater fate and toxicity. They did this by introducing a bioavailability factor BF, into the calculation of CTP and thus CF. The method of Gandhi et al. $(2010,2011)$ incorporated in USEtox ${ }^{\mathrm{TM}}$ allows the LCA practitioner to specify water chemistry by choosing among freshwater archetypes. The method has been evaluated for the cationic metals $\mathrm{Cd}, \mathrm{Co}, \mathrm{Cu}, \mathrm{Ni}, \mathrm{Pb}$, and $\mathrm{Zn}$. Thus, to calculate a metal CTP for a water archetype, the model calculates BF and $\log K_{d}$ values in WHAM 6.0 or another geochemical model, FF using value of $\log K_{d}$ obtained from WHAM 6.0 in USEtox ${ }^{\mathrm{TM}}$, and EF using the average chronic ecotoxicity of a metal using a BLM (Di Toro et al. 2001) to normalize metal bioavailability in toxicity tests relative to the water chemistry of the archetype. Details of the modeling method are described by Gandhi et al. (2010). We used 1,4-DCB as the reference chemical to normalize metal CFs for each freshwater chemistry (see Table 1).

In this analysis, we calculated CTPs and CFs for seven freshwater archetypes that we are proposing based on our analysis of global freshwater systems. These freshwater archetypes are diverse in terms of chemistry parameters (Table S4, Electronic Supplementary Material) and are environmentally abundant. We assumed that the amount of total metal listed in the LCI was the sum of its amount in total dissolved (or soluble) and particulate phases. The total dissolved phase was further divided into the colloidal phase, which is mainly associated with dissolved organic carbon (DOC) and the truly dissolved fraction. We further assumed that the bioavailable fraction of metal is within the truly dissolved fraction and is predominantly the free metal ion (see Fig. 1 in Diamond et al. 2010). We used the default database of stability constants for metal complexes in WHAM 6.0 to calculate values of $\mathrm{BF}$ and $\log K_{d}$ for each freshwater archetype (reported in Table S5, Electronic Supplementary Material). Default environmental properties of the freshwater com- 
Fig. 1 Relative contribution of metals towards total freshwater ecotoxicity potential (toxicity impact indicator) based on the model-specific CFs (1,4-DCB eq.) for a unit emission of each metal to the freshwater compartment of USEtox ${ }^{\mathrm{TM}}$

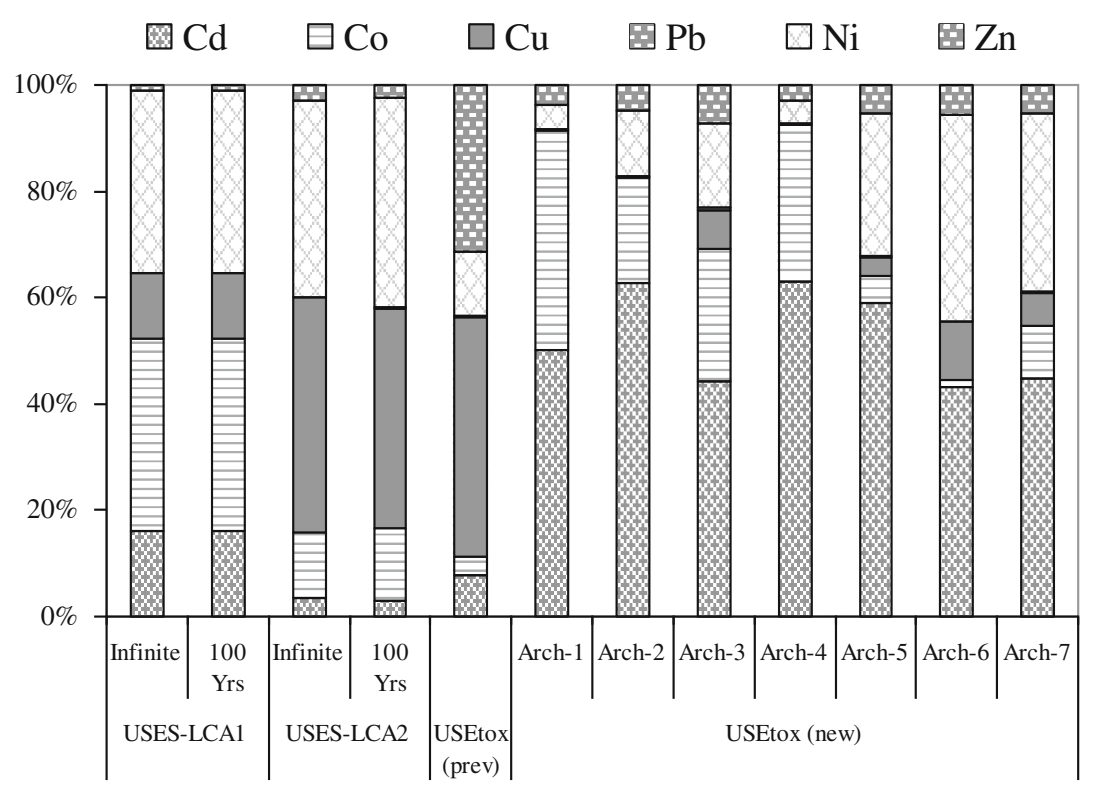

partment at the continental scale in USEtox ${ }^{\mathrm{TM}}$ were used to calculate FFs.

Chronic metal-specific BLMs were used to calculate $\mathrm{EC}_{50}$, and then $\mathrm{HC}_{50}$ and $\mathrm{EFs}$ for each archetype. BLMs are, however, either under development or not available for many metals, several of which are listed in LCI data of the case studies. For the metals $\mathrm{Cd}, \mathrm{Co}$, and $\mathrm{Pb}$, we used the free ion activity model (FIAM; Campbell 1995) to replace BLMs. In a separate exercise, we showed that the estimates of EF from FIAM are comparable to those from BLM for metals for which BLMs are currently available (e.g., $\mathrm{Cu}$, $\mathrm{Ni}$, and $\mathrm{Zn}$ ). Our results showed that the largest gain in accuracy using the new method is achieved by correcting for metal bioavailability (which if not corrected can result in differences of up to $\sim 3-4$ orders of magnitude) than by the choice of method by which the bioavailability correction is made (which can change the results by within 1 order of magnitude).

For both BLM and FIAM calculations, aquatic species-specific chronic effects data (e.g., $\mathrm{EC}_{50}$ ) for major trophic or taxonomic groups were taken from the literature. The geometric mean or $\mathrm{HC}_{50}$ of species-specifc $\mathrm{EC}_{50}$ values corrected for metal bioavailability was used to calculate an archetype-specific EF (see Table 1 and Table S5). We used the same trophic/taxonomic group to obtain chemistry-corrected values of $\mathrm{HC}_{50}$ for all archetypes, e. g., the ecosystem structure was assumed to be the same for all archetypes. This is a weakness of the modeling approach since ecosystem composition strongly depends on local environmental conditions, such as aquatic chemistry and tolerance developed by organisms to continuous exposure to metals over the long term (e.g., Forbes and Calow 2002).

\subsection{Scope and assumptions}

We limited the scope of this study to evaluating only the freshwater ecotoxicity potential of metals quantified in the LCIs of the two case studies. This exercise was not intended to compare the relative human health and environmental performance of $\mathrm{Cu}$ pipe or $\mathrm{Zn}$ gutters and/ or to provide/support information for decision making directly related to these case studies. Rather, we investigated the effect of considering metal-specific chemistry in the context of CFs for freshwater ecological toxicity. In line with this scope, we also did not consider the emissions of organic chemicals in this analysis. Finally, we further limited the scope of the study to metals - $\mathrm{Cd}, \mathrm{Cu}, \mathrm{Co}, \mathrm{Pb}, \mathrm{Ni}$, and $\mathrm{Zn}-$ for which USEtox ${ }^{\mathrm{TM}}$ (new) is currently applicable. This limitation was imposed by insufficient toxicity test data to run either chronic BLM or FIAM for $\mathrm{As}, \mathrm{Au}, \mathrm{Ag}, \mathrm{Cr}$, and $\mathrm{Hg}$ that would permit us to correct for the bioavailability of these metals in the freshwater archetypes. It is important to note here that none of the models considered in this study can calculate $\mathrm{CFs}$ for $\mathrm{Al}$ and $\mathrm{Fe}$, and therefore these metals were also excluded from the analysis.

The following are the major assumptions common to all model applications for analyzing these case studies. Both inventories specify most metal emissions to air followed by emissions to water. Differing percentages of metal emissions to air are transferred to water according to model FFs. Here, we use freshwater ecotoxicity CFs for the fraction of metals emitted to air that is transferred to water, as well as metals emitted directly to water. The ecotoxicity of metals emitted to other compartments are not included in this discussion because modeling methods for these other compartments have not been updated. 
Further, we assumed that metals listed in the LCIs of both case studies were emitted in a soluble and labile form (e.g., $\mathrm{Me}^{2+}$ ) that is readily available to complex with various inorganic and organic natural ligands present in the environment. This is a critical assumption in terms of assessing total bioavailability and fate of emitted metals because often a fraction of metal is emitted as a nonreactive, insoluble native metal or metal composite product that is not subject to multimedia transport and is not bioavailable. Therefore, this assumption may lead to overestimation of both BF and FF, and thus CTP. The ecotoxicity characterization of insoluble metal compounds requires the use of an additional model or procedure to estimate metal dissolution (e.g., Skeaff et al. 2000); however, incorporating such details in LCIA calculations is often constrained by the LCI data that do not specify the forms of metal emitted into the environment.

\section{Results and discussion}

\subsection{Comparison of metal CFs}

First, we compared the previously reported metal CFs from USES-LCA 1.0 (e.g., Huijbregts et al. 2000) that are recommended for use in LCIA, with those estimated using the USEtox ${ }^{\mathrm{TM}}$ (new) method. The previous method ranked metals amongst the most toxic chemicals in terms of both effect thresholds and time-integrated toxicity (Huijbregts et al. 2000; Payet and Jolliet 2002). The range of archetype-specific CFs calculated using the USEtox ${ }^{\mathrm{TM}}$ (new) method were consistently lower by up to 3 orders of magnitude (e.g., $\mathrm{Cu}$ ) than the previous values (see Table 2). The greatest difference in the new and previous CFs was found for $\mathrm{Cu}$, followed by $\mathrm{Ni}, \mathrm{Co}$, and $\mathrm{Pb}$ (within 2 orders of magnitude), whereas the least difference was observed for $\mathrm{Cd}$ and $\mathrm{Zn}$ (1 order of magnitude). The range of variability of new metal CFs for the seven archetypes was

Table 2 Comparison of previously reported (USES-LCA 1.0; Huijbregts et al. 2000) and a range of archetype-specific metal CFs (kg eq. 1,4-DCB) calculated using the method of Gandhi et al. (2010, 2011) for use in LCIA

Metal Previous CFs USES-LCA 1.0 Range of archetype-specific CFs USEtox ${ }^{\mathrm{TM}}$ (new)

\begin{tabular}{lll}
\hline $\mathrm{Cd}$ & $1.5 \times 10^{3}$ & $1 \times 10^{2}-4.7 \times 10^{2}$ \\
$\mathrm{Co}$ & $3.4 \times 10^{3}$ & $1.7 \times 10^{1}-8.7 \times 10^{1}$ \\
$\mathrm{Cu}$ & $1.2 \times 10^{3}$ & $2.8 \times 10^{-1}-1.2 \times 10^{2}$ \\
$\mathrm{~Pb}$ & 9.6 & $6.8 \times 10^{-2}-1.6$ \\
$\mathrm{Ni}$ & $3.2 \times 10^{3}$ & $9.5-4.1 \times 10^{2}$ \\
$\mathrm{Zn}$ & $9.2 \times 10^{1}$ & $7.5-5.9 \times 10^{1}$ \\
\hline
\end{tabular}

greatest for $\mathrm{Cu}$, followed by $\mathrm{Ni}$ and $\mathrm{Pb}(2$ orders of magnitude) and finally for $\mathrm{Zn}, \mathrm{Co}$, and $\mathrm{Cd}$ (within 1 order of magnitude). A larger range in variability of $\mathrm{CFs}$ for $\mathrm{Cu}$, $\mathrm{Ni}$, and $\mathrm{Pb}$ illustrates the importance of considering metal speciation and bioavailability while conducting LCIA of metal emissions.

Next, we compared the CFs estimated using the other models considered in this study. Metal CFs varied $\sim 3$ orders of magnitude within one model for all metals relevant to the case studies and $\sim 3$ orders of magnitude for each metal across the models (see Table 3). The lowest CF (least toxic) was consistently estimated for $\mathrm{Pb}$; however, the highest $\mathrm{CF}$ (most toxic) differed depending on the model. For example, the highest CFs from USES-LCA 1.0 and USES-LCA 2.0 were for $\mathrm{Co}$ and $\mathrm{Cu}$, respectively. $\mathrm{Cu}$ had the highest $\mathrm{CF}$ in USEtox $^{\mathrm{TM}}$ (previous), whereas $\mathrm{Cd}$ consistently had the highest CF in USEtox ${ }^{\mathrm{TM}}$ (new) for all freshwater archetypes. Note that we did not consider $\mathrm{Ag}$ for this analysis in absence of chronic BLMs that prevented us from calculating its freshwater archetype-specific EFs in the USEtox ${ }^{\mathrm{TM}}$ (new) model calculations. However, if Ag were included in this analysis then its CF was highest in USES-LCA 2.0 and USEtox $^{\mathrm{TM}}(\sim 3.5$ times higher than $\mathrm{Cu}$; results not shown).

The differences amongst CFs can be related back to the choice of $K_{d}$ s for all models except USEtox ${ }^{\mathrm{TM}}$ (new) for which $K_{d}$ S were explicitly calculated according to specified water chemistries. More importantly, EFs differed as a result of differing calculation methods used that spanned the use of PNEC for USES-LCA 1.0 to $\mathrm{HC}_{50}$ for the other models. USEtox ${ }^{\mathrm{TM}}$ (new) corrects the $\mathrm{HC}_{50}$ for chemistryspecific bioavailability, unlike the other models. For example, values of $\log K_{d}$ for Co was 3.6 for the USES-LCA models but was 4.6 for USEtox ${ }^{\mathrm{TM}}$ (previous), and for $\mathrm{Zn}$ was 5.0 in both USES-LCA models and 2.7 for USEtox ${ }^{\mathrm{TM}}$ (previous; see Table S3, Electronic Supplementary Material). In comparison, values of $\log K_{d}$ calculated for USEtox ${ }^{\mathrm{TM}}$ (new) for Co and Zn were 4.1-5.3 and 4.6-5.4, respectively, depending on the archetype (Table S5, Electronic Supplementary Material). Examples of differences among models for PNEC and $\mathrm{HC}_{50}$ are also listed in Tables $\mathrm{S} 3$ and $\mathrm{S} 5$ (Electronic Supplementary Material). For $\mathrm{Ni}$, these values ranged from 0.0018 (USES-LCA 1.0), 0.88 (USES-LCA 2.0), 1.4 (USEtox $^{\mathrm{TM}}$ (previous)) to 0.0372 to 0.1 (USEtox ${ }^{\mathrm{TM}}$ (new)).

The consideration of time scale (i.e., infinite vs. 100 years) in both USES-LCA 1.0 and USES-LCA 2.0 calculations did not significantly change the magnitude of $\mathrm{CFs}$ and thus relative ranking of metals for their potential to cause toxicity in freshwater (Table 3 and Table S6, Electronic Supplementary Material). In general, CFs for 100 years impact period were similar or slightly lower than those for infinite time. This insignificant difference may be because both models treat long-term (infinite time scale) release of metals in the same way as short-term 
Table 3 Comparison of metal CFs (kg eq. 1,4-DCB) estimated for freshwater ecotoxicity using four LCIA models, time scales of infinity and 100 years of environmental impacts after metal emissions, and for seven freshwater types as mentioned in the text

\begin{tabular}{|c|c|c|c|c|c|c|c|c|c|c|c|c|}
\hline \multirow[t]{2}{*}{ Metal } & \multicolumn{2}{|c|}{ USES-LCA 1.0} & \multicolumn{2}{|c|}{ USES-LCA 2.0} & \multirow{2}{*}{$\begin{array}{l}\text { USEtox }^{\mathrm{TM}} \\
\text { (previous) }\end{array}$} & \multicolumn{7}{|c|}{ USEtox $^{\mathrm{TM}}$ (new) } \\
\hline & Infinite & 100 Years & Infinite & 100 Years & & $\begin{array}{l}\text { Arche } \\
\text { type } 1\end{array}$ & $\begin{array}{l}\text { Arche } \\
\text { type } 2\end{array}$ & $\begin{array}{l}\text { Arche } \\
\text { type } 3\end{array}$ & $\begin{array}{l}\text { Arche } \\
\text { type } 4\end{array}$ & $\begin{array}{l}\text { Arche } \\
\text { type } 5\end{array}$ & $\begin{array}{l}\text { Arche } \\
\text { type } 6\end{array}$ & $\begin{array}{l}\text { Arche } \\
\text { type } 7\end{array}$ \\
\hline $\mathrm{Cd}$ & $1.52 \mathrm{E}+03$ & $1.51 \mathrm{E}+03$ & $9.05 \mathrm{E}+00$ & $7.13 \mathrm{E}+00$ & $9.88 \mathrm{E}+00$ & $1.02 \mathrm{E}+02$ & $1.65 \mathrm{E}+02$ & $1.56 \mathrm{E}+02$ & $1.67 \mathrm{E}+02$ & $4.73 \mathrm{E}+02$ & $4.57 \mathrm{E}+02$ & $1.51 \mathrm{E}+02$ \\
\hline $\mathrm{Co}$ & $3.41 \mathrm{E}+03$ & $3.38 \mathrm{E}+03$ & $3.30 \mathrm{E}+01$ & $3.31 \mathrm{E}+01$ & $4.17 \mathrm{E}+00$ & $8.34 \mathrm{E}+01$ & $5.19 \mathrm{E}+01$ & $8.72 \mathrm{E}+01$ & $7.79 \mathrm{E}+01$ & $4.17 \mathrm{E}+01$ & $1.66 \mathrm{E}+01$ & $3.31 \mathrm{E}+01$ \\
\hline $\mathrm{Cu}$ & $1.16 \mathrm{E}+03$ & $1.15 \mathrm{E}+03$ & $1.18 \mathrm{E}+02$ & $1.01 \mathrm{E}+02$ & $5.62 \mathrm{E}+01$ & $2.81 \mathrm{E}-01$ & $1.01 \mathrm{E}+00$ & $2.58 \mathrm{E}+01$ & $3.01 \mathrm{E}-01$ & $2.89 \mathrm{E}+01$ & $1.17 \mathrm{E}+02$ & $2.07 \mathrm{E}+01$ \\
\hline $\mathrm{Pb}$ & $9.62 \mathrm{E}+00$ & $9.62 \mathrm{E}+00$ & $4.14 \mathrm{E}-01$ & $2.93 \mathrm{E}-01$ & $3.81 \mathrm{E}-01$ & $2.43 \mathrm{E}-01$ & $8.42 \mathrm{E}-02$ & $1.64 \mathrm{E}+00$ & $9.28 \mathrm{E}-02$ & $4.15 \mathrm{E}-01$ & $6.77 \mathrm{E}-02$ & $5.56 \mathrm{E}-01$ \\
\hline $\mathrm{Ni}$ & $3.24 \mathrm{E}+03$ & $3.22 \mathrm{E}+03$ & $9.84 \mathrm{E}+01$ & $9.59 \mathrm{E}+01$ & $1.51 \mathrm{E}+01$ & $9.51 \mathrm{E}+00$ & $3.20 \mathrm{E}+01$ & $5.57 \mathrm{E}+01$ & $1.11 \mathrm{E}+01$ & $2.16 \mathrm{E}+02$ & $4.12 \mathrm{E}+02$ & $1.12 \mathrm{E}+02$ \\
\hline $\mathrm{Zn}$ & $9.17 \mathrm{E}+01$ & $9.11 \mathrm{E}+01$ & $7.52 \mathrm{E}+00$ & $6.01 \mathrm{E}+00$ & $3.92 \mathrm{E}+01$ & $7.53 \mathrm{E}+00$ & $1.29 \mathrm{E}+01$ & $2.56 \mathrm{E}+01$ & $7.93 \mathrm{E}+00$ & $4.34 \mathrm{E}+01$ & $5.93 \mathrm{E}+01$ & $1.83 \mathrm{E}+01$ \\
\hline
\end{tabular}

emissions; all models fail to consider slow, kinetically driven geochemical processes over time such as weathering and mineralization. However, time scales should become important when considering CFs for metals and organics where the latter have finite persistence versus the infinite persistence of metals.

Next, we analyzed the magnitude and relative ranking of metal CFs as a result of varying freshwater chemistry (see Table 3, Table S6). The relative ranking of chemicals is often more important than absolute values due to the comparative nature of LCIA. According to the previous CFs (USES-LCA 1.0; Huijbregts et al. 2000), Co and $\mathrm{Ni}$ were most toxic followed by $\mathrm{Cd}$ and $\mathrm{Cu}$, whereas $\mathrm{Pb}$ and $\mathrm{Zn}$ were the least toxic among these metals (see Table 2). The metal ranking in USEtox $^{\mathrm{TM}}$ (new) was a function of the effects of freshwater chemistry on metal speciation and bioavailability. USEtox ${ }^{\mathrm{TM}}$ (new) ranked $\mathrm{Cd}$ and $\mathrm{Pb}$ as the most and least toxic metals, respectively (see Table S6). The order of metal ranking between these two extremes changed from one archetype to another (see Table S6), but Ni and Co were generally more toxic than $\mathrm{Cu}$ and $\mathrm{Zn}$. For example, in archetype-1 (hard, alkaline water) the trend in CFs and thus the ecotoxicity potential was $\mathrm{Cd}>\mathrm{Co}>\mathrm{Ni}>\mathrm{Zn}>\mathrm{Cu}>\mathrm{Pb}$, whereas the pattern in archetype-5 (soft, acidic water) was $\mathrm{Cd}>\mathrm{Ni}>\mathrm{Co}>\mathrm{Cu} \approx \mathrm{Zn}$ $>\mathrm{Pb}$ (see Table S6). The CFs in USEtox ${ }^{\mathrm{TM}}$ (new) method are largely controlled by the impact of bioavailability on EF which depends on metal speciation in a specified freshwater chemistry (Gandhi et al. 2010, 2011). The bioavailability of metals is typically higher in systems with low $\mathrm{pH}, \mathrm{DOC}$, and hardness. The effect of these chemistry parameters is different for each metal as it depends on a metal's inherent geochemical characteristics. For example, $\mathrm{Cu}$ speciation is governed by the presence and amount of DOC in the freshwater, whereas $\mathrm{Zn}$ speciation is mainly controlled by the acidity of water. Thus, use of the new, archetype-specific CFs could significantly alter the outcome of LCIA studies that previously scored high ecotoxicity impacts for metal emissions. Further, the change in relative ranking of metals from one archetype to another also could change the metal that would need attention for reducing the overall freshwater ecotoxicity impact for a process/system.

The other difference between methods is the large range and variability of estimates (e.g., USES-LCA has values within the order of $10^{3}$, USEtox ${ }^{\mathrm{TM}}$ (previous) within $10^{2}$, and $\operatorname{USEtox}^{\mathrm{TM}}$ (new) ranging from $10^{-2}$ to $10^{-4}$ ) which influences not only the ranking of metals considered here, but also the ranking of these metals with respect to organic compounds (Table S8, Electronic Supplementary Material).

The differences in metal CFs for various models and freshwater archetypes can be easily summarized if we calculate total (sum) ecotoxicity of metals assuming a unit emission of each metal (Fig. 1). These results show that for the same emission, the overall ecotoxicity of these metals differs according to the model used. In USES-LCA 1.0, Ni and Co contributed the $\sim 35 \%$ each towards total ecotoxicity followed by $\mathrm{Cd}(\sim 15 \%)$ and $\mathrm{Cu}(\sim 10 \%)$. In USES-LCA 2.0 , the total ecotoxicity was mainly due to $\mathrm{Cu}$ and $\mathrm{Ni}$. Thus, $\mathrm{Cu}$ became significantly more important in the LCIA using USES-LCA 2.0. In contrast to both USES-LCA models, $\mathrm{Cu}$ and $\mathrm{Zn}$ contributed more towards total freshwater ecotoxicity when using USEtox ${ }^{\mathrm{TM}}$ (previous). Here the contribution of $\mathrm{Zn}$ is surprisingly high at $35 \%$, which decreases the relative contribution of $\mathrm{Ni}$ towards total ecotoxicity. The high $\mathrm{CF}$ estimate of $\mathrm{Zn}$ in USEtox ${ }^{\mathrm{TM}}$ (previous) is due to the use of a low $\log K_{d}$ value which results in a higher dissolved fraction (61\%) relative to the other models.

For USEtox ${ }^{\mathrm{TM}}$ (new), Cd contributed up to $65 \%$ to total ecotoxicity scores, followed by $\mathrm{Co}$ and $\mathrm{Ni}$ in all archetypes in contrast to $\mathrm{Zn}, \mathrm{Cu}$, and $\mathrm{Pb}$ that contributed minimally to total toxicity (see Fig. 1).

\subsection{Freshwater ecotoxicity of case studies}

\subsubsection{Case study: Cu pipe}

The results for the $\mathrm{Cu}$ case study were significantly different among the six model approaches. During the 
processing of $\mathrm{Cu}$ pipe, the total estimated incremental metal emissions to freshwater ranged from $<0.1 \mathrm{~g}$ to $<0.1 \mathrm{mg}$ in the order of $\mathrm{Cu}>\mathrm{Pb}>\mathrm{Zn}>\mathrm{As}>\mathrm{Ni}>\mathrm{Cd} \approx \mathrm{Cr}>\mathrm{Co}>\mathrm{Ag}>\mathrm{Hg}$ (Fig. S1, Electronic Supplementary Material). Metal emissions to air were consistently higher by a factor of $2(\mathrm{Ni})$ to $10,000(\mathrm{Ag})$ than to freshwater. These emissions were then transported from air to freshwater.

Total freshwater ecotoxicity scores for the emissions of metals to both air and water compartments (see Table S1) ranged $>3$ orders of magnitude depending on the model and water chemistry considered, but were dominated by emissions to air that were transferred to freshwater (Fig. 2). $\mathrm{Cu}$ emissions contributed $70-94 \%$ towards the total freshwater ecotoxicity scores for USES-LCA 1.0, USESLCA 2.0, and USEtox ${ }^{\mathrm{TM}}$ models (Table 4). The $\mathrm{Cu}$ contribution to the freshwater ecotoxicity score in USEtox ${ }^{\mathrm{TM}}$ (previous) was high because of its high emissions and because the $\mathrm{CF}$ for $\mathrm{Cu}$ emissions to continental air was the highest amongst all metals considered. Consistently, Co and $\mathrm{Pb}$ emissions to water contributed the least $(<0.01 \%)$ towards the total ecotoxicity scores for all models. Although $\mathrm{Cu}$ contributed the most according to USES-LCA 1.0 and USES-LCA 2.0, the two impact periods yielded different results (see Table 4). $\mathrm{Cu}$ emissions to air dominated the overall ecotoxicity scores for the infinite time scale, whereas $\mathrm{Cu}$ emissions to both air and water contributed equally at $\sim 40 \%$ for the 100 years impact period. $\mathrm{Cu}$ and $\mathrm{Ni}$ emissions to water also contributed significantly (13-25\%) towards ecotoxicity in the analysis of 100 years of metal impact.

The relative contribution of each metal to overall ecotoxicity was different for all the models (Fig. 3a, b). $\mathrm{Cu}$ contributed $72-89 \%$ towards the total ecotoxicity for USES-LCA 1.0 and 2.0, and USEtox ${ }^{\mathrm{TM}}$ (previous) due to its emission to air and (less so) water. The same was true for USEtox $^{\mathrm{TM}}$ (new) for the four archetypes-3, 5, 6, and 7 (see Table 4). These systems generally have high bioavailability of $\mathrm{Cu}$ mainly due to low DOC and $\mathrm{pH}$ (see Table S4). In contrast, Cd (42-62\%) followed by Zn (15-20\%) emissions to air contributed the most towards total ecotoxicity for archetypes 1,2, and 4, despite their lower contribution to emissions than $\mathrm{Cu}$ (see Table 4, Fig. 3a). These archetypes are characterized by high $\mathrm{pH}, \mathrm{DOC}$, and hardness. Similar to other models, metal emissions to air dominated the total ecotoxicity; however $\mathrm{Ni}$ and $\mathrm{Zn}$ emissions to water were also important contributors to USES-LCA 1.0 and USEtox (new; see Table 4, Fig. 3b).

\subsubsection{Case study: Zn gutter}

The results of the $\mathrm{Zn}$ gutter case study were more consistent and clear amongst models than those for the $\mathrm{Cu}$ case study since the inventory consisted of $92 \% \mathrm{Zn}$ emissions when $\mathrm{Al}$ and $\mathrm{Fe}$ were excluded from this analysis. Total emissions of each metal to freshwater spanned $>4$ orders of magnitude $(<10 \mathrm{~g}$ to $<1 \mathrm{mg}$ ) from $\mathrm{Al}$ and $\mathrm{Fe}$, through to $\mathrm{Zn}$ and $\mathrm{Pb}$; emissions of $\mathrm{Cr}, \mathrm{Cu}$, and Ni were low (see Table S2, Fig. S3, Electronic Supplementary Material). $\mathrm{Zn}$ emissions were two times higher to air than to freshwater. $\mathrm{Cr}, \mathrm{Cu}, \mathrm{Pb}$, and $\mathrm{Ni}$ were emitted to air only, whereas $\mathrm{Al}$ and $\mathrm{Fe}$ were emitted to freshwater only (see Table S2). As mentioned earlier, none of the models considered in this study were able to calculate $\mathrm{CFs}$ for $\mathrm{Al}$ and $\mathrm{Fe}$ and therefore they were omitted.

The variability in total ecotoxicity spanned nearly 4 orders of magnitude due to differences in the model approaches and freshwater chemistry of the receiving environment (Fig. 4). The highest and lowest total ecotoxicity scores were estimated by USEtox ${ }^{\mathrm{TM}}$ (previous) and USES-LCA 2.0 models, respectively. Both USES-LCA 1.0 and USES-LCA 2.0 had comparable estimates for the infinite and 100 years time scales of impacts. For USEtox $^{\mathrm{TM}}$ (new) the highest scores were for archetypes 6 followed by 5 (see Fig. 3); these freshwaters are character-
Fig. 2 LCIA results presented as the total freshwater ecotoxicity score of metals estimated for the $\mathrm{Cu}$ case study. Here, ecotoxicity was estimated for total emissions of metals to freshwater due to release of metals to air and water compartments during the processing of $\mathrm{Cu}$ pipe (see Table S1)

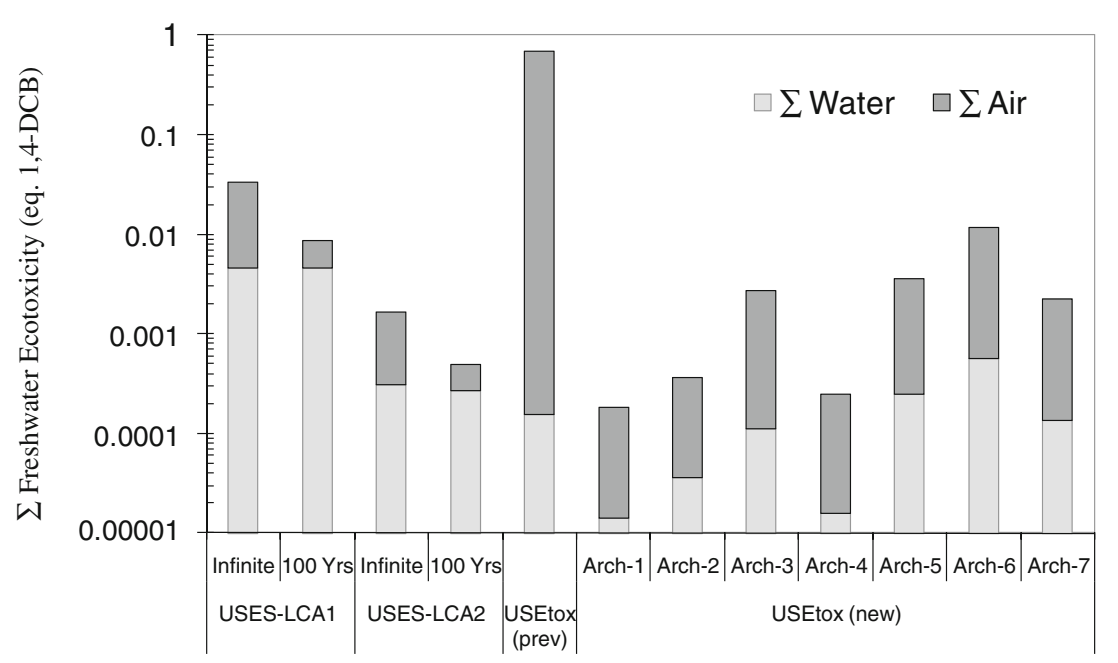


Table 4 Percentage contribution of metal emissions to air and water towards the total freshwater ecotoxicity estimated for $\mathrm{Cu}$ pipe case study

\begin{tabular}{|c|c|c|c|c|c|c|c|c|c|c|c|c|}
\hline \multirow[t]{2}{*}{ Metals } & \multicolumn{2}{|c|}{ USES-LCA 1.0} & \multicolumn{2}{|c|}{ USES-LCA 2.0} & \multirow{2}{*}{$\begin{array}{l}\text { USEtox }^{\mathrm{TM}} \\
\text { Prev } \\
(\%)\end{array}$} & \multicolumn{7}{|c|}{ USEtox $^{\mathrm{TM}}$ (new) } \\
\hline & $\begin{array}{l}\text { Infinite } \\
(\%)\end{array}$ & $\begin{array}{l}100 \text { Years } \\
(\%)\end{array}$ & $\begin{array}{l}\text { Infinite } \\
(\%)\end{array}$ & $\begin{array}{l}100 \text { Years } \\
(\%)\end{array}$ & & $\begin{array}{l}\text { Arch } 1 \\
(\%)\end{array}$ & $\begin{array}{l}\text { Arch } 2 \\
(\%)\end{array}$ & $\begin{array}{l}\text { Arch } 3 \\
(\%)\end{array}$ & $\begin{array}{l}\text { Arch } 4 \\
(\%)\end{array}$ & $\begin{array}{l}\text { Arch } 5 \\
(\%)\end{array}$ & $\begin{array}{l}\text { Arch } 6 \\
(\%)\end{array}$ & $\begin{array}{l}\text { Arch } 7 \\
(\%)\end{array}$ \\
\hline Cd (air) & 1.94 & 1.34 & 0.11 & 0.09 & 0.29 & 51.33 & 42.02 & 5.31 & 62.29 & 12.22 & 3.58 & 6.15 \\
\hline Co (air) & 0.25 & 0.44 & 0.04 & 0.07 & 0.01 & 2.71 & 0.85 & 0.19 & 1.88 & 0.07 & 0.01 & 0.09 \\
\hline $\mathrm{Cu}$ (air) & 80.87 & 44.44 & 80.07 & 44.91 & 93.40 & 13.55 & 24.55 & 83.81 & 10.77 & 71.27 & 87.13 & 80.65 \\
\hline $\mathrm{Pb}$ (air) & 0.15 & 0.03 & 0.09 & 0.02 & 0.12 & 1.78 & 0.31 & 0.81 & 0.50 & 0.15 & 0.01 & 0.33 \\
\hline Ni (air) & 2.60 & 1.11 & 0.68 & 0.49 & 0.28 & 3.01 & 5.10 & 1.19 & 2.61 & 3.49 & 2.02 & 2.87 \\
\hline Zn (air) & 0.56 & 0.25 & 0.41 & 0.27 & 5.88 & 19.89 & 17.20 & 4.54 & 15.50 & 5.87 & 2.42 & 3.92 \\
\hline Cd (water) & 0.02 & 0.08 & 0.00 & 0.01 & 0.00 & 0.26 & 0.21 & 0.03 & 0.32 & 0.06 & 0.02 & 0.03 \\
\hline Co (water) & 0.00 & 0.00 & 0.00 & 0.00 & 0.00 & 0.00 & 0.00 & 0.00 & 0.00 & 0.00 & 0.00 & 0.00 \\
\hline $\mathrm{Cu}$ (water) & 6.73 & 25.84 & 14.05 & 39.77 & 0.02 & 0.30 & 0.55 & 1.88 & 0.24 & 1.60 & 1.95 & 1.81 \\
\hline $\mathrm{Pb}$ (water) & 0.00 & 0.01 & 0.00 & 0.01 & 0.00 & 0.02 & 0.00 & 0.01 & 0.00 & 0.00 & 0.00 & 0.00 \\
\hline Ni (water) & 6.65 & 25.57 & 4.16 & 13.33 & 0.00 & 3.64 & 6.17 & 1.43 & 3.15 & 4.22 & 2.44 & 3.47 \\
\hline Zn (water) & 0.23 & 0.88 & 0.39 & 1.02 & 0.00 & 3.51 & 3.04 & 0.80 & 2.74 & 1.04 & 0.43 & 0.69 \\
\hline
\end{tabular}

Note that six metals for which new CFs are currently available were considered in this analysis

Fig. 3 Relative contribution of each metal emitted to a air and $\mathbf{b}$ water as listed in LCI towards the total freshwater ecotoxicity score for the LCIA of $\mathrm{Cu}$ case study

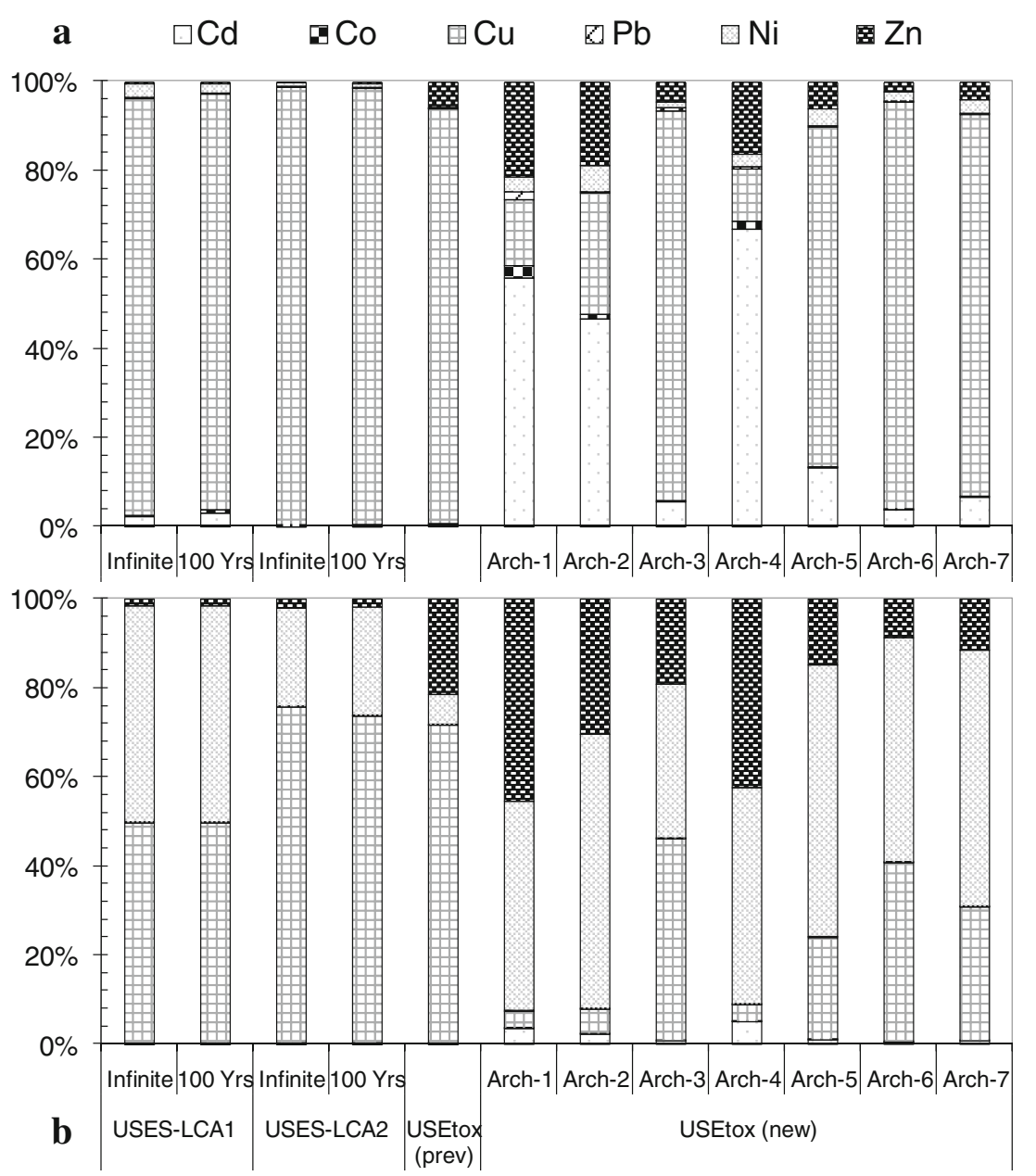


Fig. 4 LCIA results presented as the total freshwater ecotoxicity score of metals estimated for the $\mathrm{Zn}$ case study. Here, the ecotoxicity was estimated for total emission of metals to freshwaters due to release of metals to air and water compartments as listed in LCI data for Zn gutter system (see Table S2)

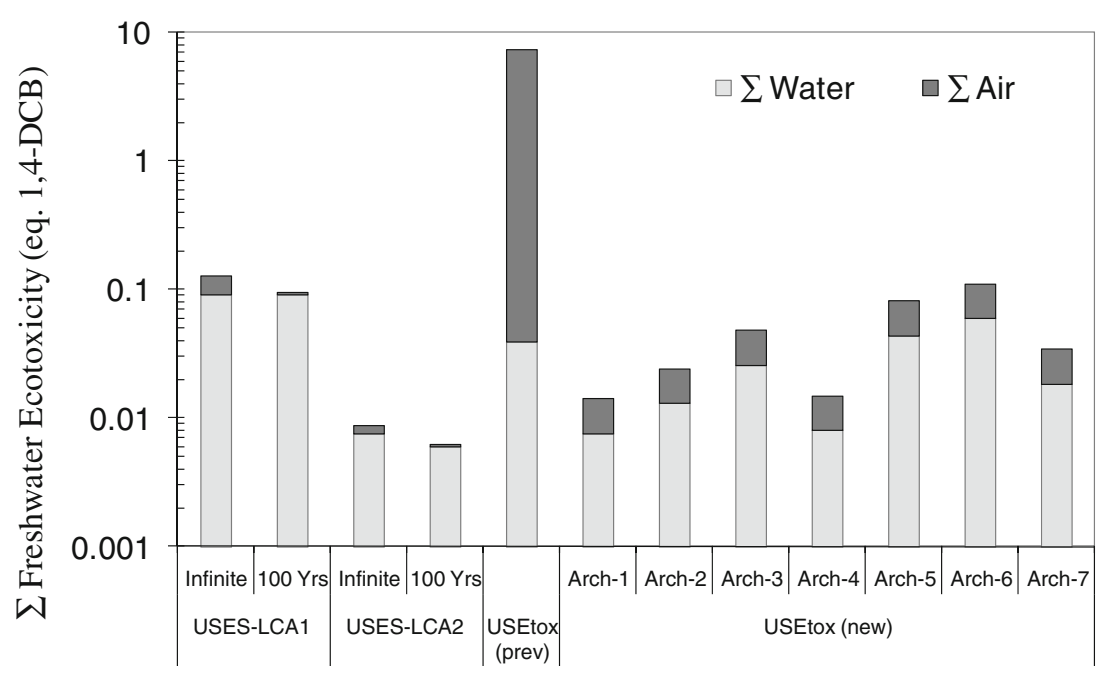

ized by low $\mathrm{pH}$ and low hardness (see Table S4). The lowest ecotoxicity scores were estimated for freshwater archetypes 1 and 4 (see Fig. 3), which have high hardness and $\mathrm{pH}$ values above circumneutral (see Table 3). $\mathrm{Zn}$ contributed $\sim 98 \%$ towards the total scores in all models and freshwater archetypes because it completely dominated the inventory (Fig. 5). $\mathrm{Cu}, \mathrm{Pb}$, and $\mathrm{Ni}$ were approximately equal contributors within the fraction $(<2 \%)$ contributed by other metals. For USES-LCA models, Zn emissions to water contributed the most towards total ecotoxicity, whereas in USEtox ${ }^{\mathrm{TM}}$ (new) $\mathrm{Zn}$ emission to air contributed the most (see Fig. 5). In contrast, Zn emissions to both air and water contributed equally towards total ecotoxicity for all freshwater archetypes. The differences in freshwater chemistry had negligible effects on the overall freshwater ecotoxicity of the $\mathrm{Zn}$ case study.

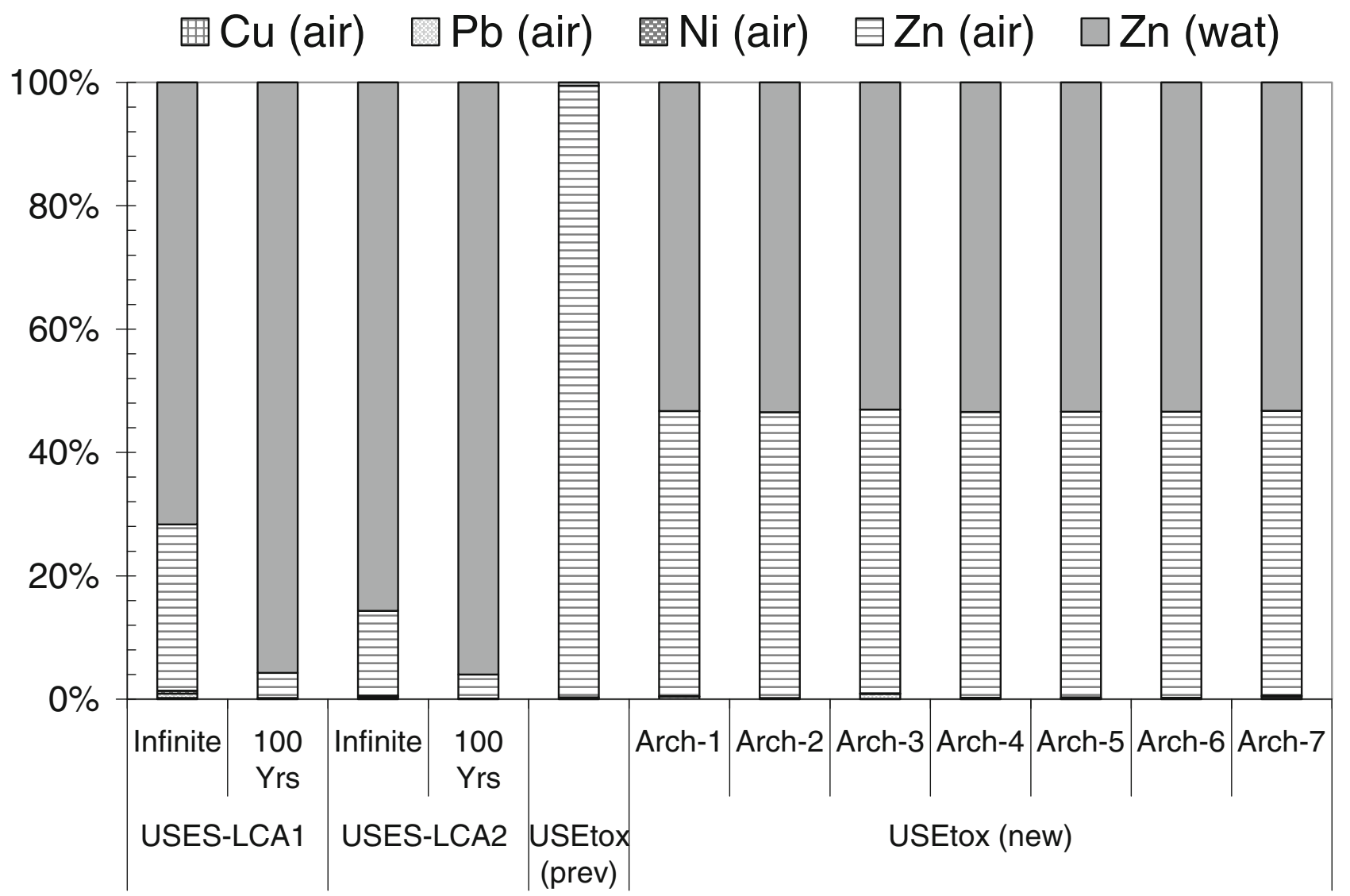

Fig. 5 Contribution of each metal listed in LCI of Zn gutter system towards the total freshwater ecotoxicity score in the analysis of its LCIA 


\subsubsection{Comparisons with previous case study results}

Comparisons of the results from this study with those reported by Gloria et al. (2006) revealed differences of up to 4 orders of magnitude in total ecotoxicity estimates for both case studies depending on the model used. For the $\mathrm{Cu}$ pipe case study, although $\mathrm{Cu}$ consistently had the highest ecotoxicity in all models considered by Gloria et al. (2006), $\mathrm{Zn}$ (in CalTOX), Cd (in EDIP 97), and Zn and Cd (in EI 99 HA) had low but significant contributions. The results of USEtox $^{\mathrm{TM}}$ (new) in this exercise also suggested important contributions to ecotoxicity of $\mathrm{Zn}, \mathrm{Cd}$, and $\mathrm{Ni}$, in addition to $\mathrm{Cu}$. For the $\mathrm{Zn}$ gutter case study, Gloria et al. (2006) only considered $\mathrm{Pb}$ and $\mathrm{Zn}$ in their comparative analysis due to several limitations of the models to provide CFs for other metals.

\subsubsection{Improvements in USEtox ${ }^{T M}$ (new) approach}

As with all models of natural systems, the performance of the USEtox ${ }^{\mathrm{TM}}$ (new) approach in the context of LCIA has not been, and nor can it be, rigorously evaluated (Oreskes et al. 1994). Verification and validation of LCIA results based on these models is particularly not possible since LCA is concerned with the incremental emission of a substance associated with the functional unit of a product over its life cycle, which is regarded as a pulse (in $\mathrm{kg}$ ) and lacks a time dimension (Guinée and Heijungs 1993). The model can be partially evaluated if applied in a site-specific risk assessment rather than LCIA since the goal of the LCIA exercise is to estimate the marginal change in the adverse effect as a function of the marginal change in emission to an evaluative system. However, the submodels used in USEtox $^{\mathrm{TM}}$ (new) to calculate metal speciation/bioavailability (WHAM 6.0) and toxicity (BLMs) have been evaluated in literature as far as practically possible.

Although CF is a linear function of BF, FF, and EF, it is challenging to assess the overall performance of CFs generated by the USEtox ${ }^{\mathrm{TM}}$ (new) model in the context of varying water chemistry since both $\mathrm{BF}$ and $\mathrm{EF}$ vary nonlinearly as a function of this chemistry. For an evaluative environment, metal CFs are mainly controlled by $\mathrm{BF}$ and then EF (Gandhi et al. 2010, 2011). CFs calculated using USEtox ${ }^{\mathrm{TM}}$ (new) adequately addressed these effects by using WHAM and BLM. For example, according to the chronic toxicity data in the literature that were assembled to derive EFs for USEtox ${ }^{\mathrm{TM}}$ (new), the ranking of geometric mean values of chronic $\mathrm{EC}_{50}$ 's was $\mathrm{Cd}>\mathrm{Cu}>\mathrm{Pb}>\mathrm{Ni}>\mathrm{Zn}>\mathrm{Co}$. However, because the range of $\mathrm{EC}_{50}$ values for individual metals such as $\mathrm{Zn}$ was up to 4 orders of magnitude depending on water chemistry, this ranking is not absolute; there is considerable overlap among the ranges of each metal (Table S7,
Electronic Supplementary Material). Thus, changes in this order of metal toxicity ranking can occur in the EF of USEtox $^{\mathrm{TM}}$ (new) as a function of $\mathrm{pH}$, DOC and water hardness that control metal speciation to varying degrees according to the geochemical behavior of a metal. For example, $\mathrm{Zn}$ toxicity decreased by a factor of 3-8 when $\mathrm{pH}$ increased from 6.5 to 9 whereas the effect of $\mathrm{pH}$ on $\mathrm{Ni}$ toxicity became significant only at $\mathrm{pH}>8.0-8.2$ (De Schamphelaere et al. 2006a, b). These observations are captured in the $\mathrm{HC}_{50}$ estimates and thus CFs of USEtox $^{\mathrm{TM}}$ (new; see Table S5).

\section{Conclusions}

Apeldoorn, Lausanne, and Clearwater meetings recommended that metal-specific speciation must be considered when evaluating or ranking the ecotoxicity of organic compounds and metals in the contexts of hazard, risk assessment and LCA. We evaluated the implications of considering metal speciation, and specifically bioavailability, on estimates of potential freshwater ecotoxicity, by introducing the method of Gandhi et al. (2010) into USEtox ${ }^{\mathrm{TM}}$ (new) in comparison to previous methods (USES-LCA 1.0, 2.0, USEtox ${ }^{\mathrm{TM}}$ (previous)) that did not account for metal speciation. The comparison was made using the inventories of two case studies of $\mathrm{Cu}$ pipe and $\mathrm{Zn}$ gutters (Gloria et al. 2006). By accounting for metal bioavailability, we estimated 1-4 orders of magnitude lower overall freshwater ecotoxicity scores $(\Sigma \mathrm{CF} \times$ emissions, calculated using USEtox ${ }^{\mathrm{TM}}$ (new)) for both case studies, in comparison to estimates from the other models, and 1-2 orders of magnitude lower ecotoxicity for the $\mathrm{Cu}$ pipe case study with previously published CFs calculated using USESLCA 1.0 (Huijbregts et al. 2000). The range in these differences is due to the choice of freshwater chemistry, as illustrated through the use of seven freshwater archetypes in the USEtox ${ }^{\mathrm{TM}}$ (new) calculations. Contributions of each metal to the total scores also changed due to the consideration of metal bioavailability and speciation in USEtox ${ }^{\mathrm{TM}}$ (new). The latter can be summarized by the change in rank order of metal CFs of USES-LCA 1.0 as $\mathrm{Co}>\mathrm{Ni}>\mathrm{Cd} \approx \mathrm{Cu}>\mathrm{Zn}>\mathrm{Pb}$, versus USEtox $^{\mathrm{TM}}$ (new) as $\mathrm{Cd}>\mathrm{Co}>\mathrm{Ni}>\mathrm{Zn}>\mathrm{Cu}>\mathrm{Pb}$ for the archetype of hard alkaline water and $\mathrm{Cd}>\mathrm{Ni}>\mathrm{Co}>\mathrm{Cu} \approx \mathrm{Zn}>\mathrm{Pb}$ for the archetype of soft, acidic water. For both case studies, differences in ecotoxicity scores were not significant for two time scales: infinite versus 100 years of impacts after emissions.

\section{Practical implications}

The main implication of this study is that more realistically considering metal bioavailability and its dependence on freshwater chemistry using the method of Gandhi et al. 
(2010) can decrease estimates of overall metal ecotoxicity by up to several orders of magnitude, as illustrated in the case studies. As argued by Gandhi et al. (2010), this revised assessment of freshwater ecotoxicity of metals is consistent with our current understanding of metal chemistry and ecotoxicity. These lower estimates could reduce contributions of metals, in general, to overall freshwater toxicity estimates evaluated through LCIA, as well as the ranking of individual metals and metals relative to organic compounds. The magnitude of the reduction depends on the freshwater archetype chosen since CFs can vary by up to 2 orders of magnitude for one metal among archetypes.

Acknowledgments We acknowledge funding from UNEP SETAC Life Cycle Initiative, International Council of Mining and Metals (ICMM), Iron Ore Company of Canada (IOC), Xstrata, and NSERC (CRD to Diamond, CGS to Gandhi) for this project. This work was also supported in part by the Society of Environmental Toxicology and Chemistry (SETAC) Chris Lee award to Gandhi for metals research, sponsored by the International Copper Association (ICA). Huijbregts was partly funded by the European Commission under the 7th framework program on environment; ENV.2008.3.3.2.1: PROSUITE-Sustainability Assessment of Technologies, grant agreement number 227078. We thank Bill Adams, John Atherton, and Michael Hauschild for their guidance.

Open Access This article is distributed under the terms of the Creative Commons Attribution Noncommercial License which permits any noncommercial use, distribution, and reproduction in any medium, provided the original author(s) and source are credited.

\section{References}

Adams WJ, Chapman PM (2005) Assessing the hazard of metals and inorganic metal substances in aquatic and terrestrial systems: summary of a SETAC Pellston workshop. SETAC, Pensacola

Apeldoorn (2004) Declaration of Apeldoorn on LCIA of non-ferrous metals. Results of a workshop by a group of LCA specialists, held in Apeldoorn, NL, April 15th, 2004. Int J Life Cycle Assess 9:334

Brandes LJ, Den Hollander H, Van de Meent D (1996) SimpleBox 2.0: a nested multimedia fate model for evaluating the environmental fate of chemicals, Report No. 719101029. National Institute of Public Health and the Environment (RIVM): Bilthoven, The Netherlands

Campbell PGC (1995) Interactions between trace metals and aquatic organisms: a critique of the free-ion activity model. In: Tessier A, Turner DR (eds) Metal speciation and bioavailability in aquatic systems, vol 1. Wiley, New York, pp 45-102

De Schamphelaere K, Van Laer L, Deleebeeck N, Muyssen B, Degryse F, Smolders E, Janssen C (2006a) Nickel speciation and ecotoxicity in European natural surface waters: development, refinement and validation of bioavailability models. Ghent University, Gent, Report by Laboratory for Environmental Toxicology and Aquatic Ecology

De Schamphelaere K, Heijerick DG, Janssen CR (2006b) Development and validation of biotic ligand model for predicting chronic zinc toxicity to fish, daphnids and algae. Ghent University, Gent, Report by Laboratory for Environmental Toxicology and Aquatic Ecology

Den Hollander HA, Van Eijkeren JCH, Van de Meent D (2004) SimpleBox 3.0: multimedia mass balance model for evaluating the fate of chemicals in the environment. Report No. 601200003. National Institute for Public Health and the Environment (RIVM): Bilthoven, The Netherlands

Di Toro D, Allen H, Bergman H, Meyer J, Paquin P (2001) Biotic Ligand model of the acute toxicity of metals: 1. technical basis. Environ Toxicol Chem 20(10):2383-2396

Diamond M, Gandhi N, Adams W, Atherton J, Bhavsar S, Bullé C, Campbell P, Dubreuil A, Fairbrother A, Farley K, Green A, Guinée J, Hauschild M, Huijbregts M, Humbert S, Jensen K, Jolliet O, Margni M, McGeer J, Peijnenburg W, Rosenbaum R, van de Meent D, Vijver M (2010) The Clearwater Consensus: the estimation of metal hazard in fresh water. Int J Life Cycle Assess 15:143-147

Ecobalance (2000a) Life cycle assessment of copper tube for the supply of water in residential structures: final report-Peer review. Ecobalance Price Waterhouse Coopers, Bethesda

Ecobalance (2000b) Life cycle assessment of copper tube for the supply of water in residential structures: peer review methodology report. Ecobalance Price Waterhouse Coopers, Bethesda

Finnveden G (1999) Methodological aspects of life cycle assessment of integrated solid waste management systems. Resour Conserv Recycl 26(3-4):173-187

Forbes VE, Calow P (2002) Species sensitivity distributions revisited: a critical appraisal. Hum Ecol Risk Assess 8(3):473-492

Gandhi N, Diamond ML, van de Meent D, Huijbregts MAJ, Peijnenburg WJGM, Guinée J (2010) New method for calculating comparative toxicity potential of cationic metals in freshwater: application to copper, nickel, and zinc. Environ Sci Technol 44(13):5195-5201

Gandhi N, Huijbregts MAJ, van de Meent D, Peijnenburg WJGM, Guinée J, Diamond ML (2011) Implications of geographic variability on ecotoxicity potentials of $\mathrm{Cu}, \mathrm{Ni}$ and $\mathrm{Zn}$ in freshwaters of Canadian ecoregions. Chemosphere 82(2):268-277

Gloria TP, Russell AJ, Atherton J, Baker SR, Cook M (2006) Ecological toxicity methods and metals: an examination of two case studies. Int J Life Cycle Assess 11(1):26-33

Guinée JB, Heijungs R (1993) A proposal for the classification of toxic substances within the framework of life cycle assessment of products. Chemosphere 26(10):1925-1944

Hauschild MZ, Huijbregts M, Jolliet O, MacLeod M, Margni M, van de Meent D, Rosenbaum RK, McKone TE (2008) Building a model based on scientific consensus for life cycle impact assessment of chemicals: the search for harmony and parsimony. Environ Sci Technol 42:7032-7037

Huijbregts MAJ, Thissen U, Guinée J, Jager T, Kalf D, van de Meent D, Ragas AMJ, Sleeswijk AW, Reijnders L (2000) Priority assessment of toxic substances in life cycle assessment. Part I: calculation of toxicity potentials for 181 substances with the nested multi-media fate, exposure and effects model USES-LCA. Chemosphere 41:541-573

Huijbregts MAJ, Guinée JB, Reijnders L (2001) Priority assessment of toxic substances in LCA. Part III: export of potential impact over time and space. Chemosphere 44:59-65

Jolliet O, Rosenbaum R, Chapmann PM, McKone T, Margni M, Scheringer M, van Straalen N, Wania F (2006) Establishing a framework for life cycle toxicity assessment: findings of the Lausanne review workshop. Int J Life Cycle Assess 11:209-212

Oreskes N, Shraderfrechette K, Belitz K (1994) Verification, validation, and confirmation of numerical models in the earth sciences. Science 263:641-646

Payet J, Jolliet O (2002) Comparative assessment of the toxic impact of metals on aquatic ecosystems: the AMI method. International Workshop on Life-Cycle Assessment and Metals, pp 188-191

Pettersen J, Hertwich EG (2008) Critical review: life-cycle inventory procedures for long-term release of metals. Environ Sci Technol 42:4639-4647

Rosenbaum RK, Bachmann TM, Swirsky Gold L, Huijbregts MAJ, Jolliet O, Juraske R, Koehler A, Larsen HF, MacLeod M, Margni M, McKone TE, Payet J, Schuhmacher M, van de Meent D, 
Hauschild MZ (2008) USEtox - the UNEP/SETAC toxicity model: recommended characterisation factors for human toxicity and freshwater ecotoxicity in life cycle impact assessment. Int $\mathrm{J}$ Life Cycle Assess 13:532-546

Skeaff J, Delbeke K, Van Assche F, Conard BA (2000) Critical surface area concept for acute hazard classification of relatively insoluble metal-containing powders in aquatic environments. Environ Toxicol Chem 19:1681-1691

Tipping E (1998) Humic ion-binding model VI: an improved description of the interactions of protons and metal ions with humic substances. Aquat Geochem 4:43-48
Udo de Haes HA, Jolliet O, Finnveden G, Hauschild M, Krewitt W, Müller-Wenk R (1999) Best available practice regarding impact categories and category indicators for life cycle impact assessment, part 1. Int J Life Cycle Assess 4:66-74

van de Meent D, Huijbregts MAJ (2005) Calculating life-cycle assessment effect factors from potentially affected fractionbased ecotoxicological response functions. Environ Toxicol Chem 24:1573-1578

van Zelm R, Huijbregts MAJ, van de Meent D (2009) USES-LCA 2.0-a global nested multi-media fate, exposure, and effects model. Int J Life Cycle Assess 14:282-284 